\title{
The nares as a CA-MRSA reservoir in the healthy elderly
}

\author{
Cristiane Silveira de Brito ${ }^{[1]}$, Lícia Ludendorff Queiroz ${ }^{[1]}$, Paola Amaral de Campos ${ }^{[1]}$, \\ Deivid William da Fonseca Batistão ${ }^{[1]}$, Helisângela de Almeida Silva ${ }^{[1]}$, \\ Guilherme Gularte de Agostini ${ }^{[2]}$, Paulo Pinto Gontijo Filho ${ }^{[1]}$ \\ and Rosineide Marques Ribas ${ }^{[1]}$
}

[1]. Laboratório de Microbiologia Molecular, Instituto de Ciências Biomédicas, Universidade Federal de Uberlândia, Uberlândia, Minas Gerais, Brazil. [2]. Faculdade de Educação Física, Universidade Federal de Uberlândia, Uberlândia, Minas Gerais, Brazil.

\begin{abstract}
Introduction: The frequency of methicillin-resistant Staphylococcus aureus (MRSA) has increased in the community. This study evaluated the prevalence of MRSA and community-acquired (CA)-MRSA in 120 healthy elderly. Methods: The MRSA were evaluated for the presence of the IS256, mecA, agr, icaA, icaD, fnbB, and $p v l$ genes with PCR. Results: Frequency of S. aureus and MRSA colonization was $17.8 \%$ and $19 \%$, respectively. CA-MRSA isolate showed SCCmec IV, fnbB $B^{+}$, and $i c a D^{+}$. Conclusions: CA-MRSA was detected, with genotype determined as SCCmec type IV/IS256/fnbB $/$ icaA-/icaD $/ / b b p^{-} / a g r 2 / b a p^{-} / p v l$, characterizing this population as a possible reservoir of this organism in the community.
\end{abstract}

Keywords: CA-MRSA. Elderly. Reservoir.

Over the past decade, Methicillin-resistant Staphylococcus aureus (MRSA) has been a major clinical and epidemiological problem in hospitals. It is reported with increased frequency in community populations without prior health care contact ${ }^{(1)}$. Community-acquired methicillin-resistant Staphylococcus aureus (CA-MRSA) is susceptible to the majority of nonbetalactamic antibiotics. It frequently expresses more virulent genes as $p v l$ and predominantly carries the SCCmec type $\mathrm{IV}^{(2)}$.

In colonized individuals, nasal carriage of MRSA acts as a potential endogenous reservoir for clinical infections or as a source of cross-colonization for spread in the community ${ }^{(3)}$. We conducted a cross-sectional study from November 2013 to February 2014 at the Faculty of Physical Education, Federal University of Uberlândia, and looked for MRSA in the anterior nares of 120 healthy elderly ( $\geq 60$ years) people who practiced regular physical activity. The research protocols were approved by the institutional review board, and all volunteers signed informed consent forms before the study began.

Using sterile swabs pre-moistened with Triptic Soy Broth (Becton Dickinson, Le Pont de Claix, France) we collected bacterial samples from the nares. After collecting, swabs were promptly transported to the Laboratory of Microbiology and

Corresponding author: Dra. Cristiane Silveira de Brito. Laboratório de Microbiologia/Instituto de Ciências Biomédicas/UFU. Avenida Amazonas, Bloco 4C s/n, $2^{\circ}$ andar, Campus Umuarama, 38400-902 Uberlândia, Minas Gerais, Brasil.

Phone: 5534 3291-8670

e-mail: cristianebrito_bio@yahoo.com.br

Received 27 February 2015

Accepted 20 May 2015 incubated at $35^{\circ} \mathrm{C}$, overnight. About $0.1 \mathrm{ml}$ of this suspension was inoculated onto the surface of petri dishes selected (Mannitol Salt Agar - Himedia, India) for growing S. aureus. The bacterial isolates were identified with phenotypic classical tests (isolates were tested for the production of the coagulase enzyme via the tube method, which indicates $S$. aureus and separates it from the commonly isolated negative coagulase Staphylococcus). The MRSA and the susceptibility profile to several antimicrobials (oxacillin, $1 \mu \mathrm{g}$; cefoxitin, $30 \mathrm{mg}$; ciprofloxacin, $5 \mu \mathrm{g}$; clindamycin, $2 \mu \mathrm{g}$; gentamicin, $10 \mu \mathrm{g}$; tetracycline, $30 \mu \mathrm{g}$; rifampicin, $30 \mu \mathrm{g}$; erythromycin, $15 \mu \mathrm{g}$ and sulfamethoxazole/trimethoprim, $25 \mu \mathrm{g}$ ) were confirmed with the disk diffusion method using Mueller Hinton Agar (Himedia, India). The cefoxitin-resistant isolates according to disk diffusion were confirmed based on minimum inhibitory concentration (MIC) for oxacillin by performing the E-test ${ }^{\mathbb{B}}$ (AB Biodisk, Solna, Sweden) and the presence of mecA with polymerase chain reaction (PCR). Staphylococcus aureus ATCC 25923 was preferred as a quality control strain ${ }^{(4)}$.

Purification of genomic deoxyribonucleic acid (DNA) of four isolates characterized as MRSA by disk diffusion was prepared using QIAamp DNA Mini Kit (Qiagen) according to the manufacturers recommendations. The $p v l$, icaA, icaD, IS256, agr, bap, and $f n b B$ genes were assessed with endpoint PCR according to methods described by Saï-Salim et al. ${ }^{(5)}$, Martin-Lopez et al. ${ }^{(6)}$, Arciola et al..$^{(7)}$, Gu et al. ${ }^{(8)}$, Shopsin et al. ${ }^{(9)}$, Cucarella et al. ${ }^{(10)}$ and Tristan et al. ${ }^{(11)}$. The oligonucleotide primers described previously by Kondo et al. ${ }^{(12)}$ were used for verifying the various types of SCCmec elements. Staphylococcus aureus ATCC 25923, Staphylococcus epidermidis ATCC 12228 and Clone Southwest Pacific were preferred as a quality control strain. 
TABLE 1 - Characteristics of colonized elderly people analyzed in the study.

\begin{tabular}{|c|c|c|c|c|}
\hline \multirow[t]{2}{*}{ Characteristics * } & \multicolumn{2}{|c|}{$\begin{array}{l}\text { Nares colonization } \\
\quad(\mathrm{n}=118)^{* *}\end{array}$} & \multicolumn{2}{|c|}{$\begin{array}{c}\text { Nares colonization by } \\
\text { Staphylococcus aureus } \\
(\mathrm{n}=21)\end{array}$} \\
\hline & $\mathbf{n}$ & $\%$ & $\mathbf{n}$ & $\%$ \\
\hline \multicolumn{5}{|l|}{ Sex } \\
\hline female & 90 & 76.3 & 17 & 81.0 \\
\hline \multicolumn{5}{|l|}{ Age (years) } \\
\hline $60-70$ & 56 & 47.5 & 13 & 61.9 \\
\hline $71-80$ & 40 & 33.9 & 6 & 28.6 \\
\hline$\geq 81$ & 11 & 9.3 & 0 & 0.0 \\
\hline widower & 40 & 33.9 & 2 & 9.5 \\
\hline \multicolumn{5}{|l|}{ Residents in the household } \\
\hline $1-4$ & 98 & 83.1 & 16 & 76.2 \\
\hline $5-8$ & 9 & 7.6 & 3 & 14.3 \\
\hline Time physical activity $\geq 150$ min per week & 71 & 59.2 & 16 & 76.2 \\
\hline Hospital procedure and/or hospitalization in the past 12 months & 19 & 15.8 & 3 & 14.3 \\
\hline
\end{tabular}

*It was not possible to collect information from 11 elderly individuals. **118 nares colonized of the 120 collected.

Table 1 shows that a total of $21 \mathrm{~S}$. aureus isolates were recovered from the nares of 120 subjects, and the nasal carriage rate was $17.8 \%$ (21/118 nares colonized by Staphylococcus spp.). The disk diffusion method characterized 19\% (4/21) of the isolates as MRSA and 50\% (2/4) with MIC $\geq 4 \mathrm{mg} / \mathrm{L}$ (only one multidrug resistance isolate). In total, $50 \%$ of the MRSA showed multidrug resistance with resistance to erythromycin, rifampicin, and clindamycin. On the other hand, all strains of MRSA were susceptible to ciprofloxacin, gentamicin, amikacin, tetracycline, and sulfamethoxazole/trimethoprim.

The presence of the mecA gene was confirmed in two isolates with $\mathrm{MIC} \geq 4 \mathrm{mg} / \mathrm{L}$, which carried SCCmec type II and $\mathrm{IV}$, respectively. Despite not being tested, it is possible that the other two samples detected in our search ( $m e c A^{-}$, cefoxitin resistant) have the new homologous variant mec $C$ that has $70 \%$ identity with mecA. The mecC gene is not detected with the PCR method established for the detection of mecA; consequently, isolates harboring this new variant can be misidentified and reported as methicillin-susceptible S. aureus ${ }^{(13)}$. The CA-MRSA isolated showed the following genotypic profile: SCCmec

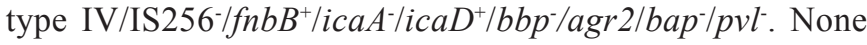
of the elderly participants colonized with MRSA had previous hospitalization or had undergone any hospital procedure in the 12 months before the study.

The majority of studies conducted to evaluate asymptomatic carriage of MRSA have been performed in individuals in the community who have had contact with a hospital environment. Studies of epidemiological surveillance for CA-MRSA carriage in healthy subjects are rare in Brazil. This study provides the first description of CA-MRSA with genotypic profile in this population.

In our study, we also detected a strain carrying the SCCmec type II. The epidemiology of MRSA is a dynamic process that brings to light the blurring of the limits between the community and hospital ${ }^{(14)}$. According to the literature, the strains carrying $\mathrm{SCCmec}$ type II are associated with clinical isolates recovered from the hospital ${ }^{(2)}$. One possible explanation for this is that the elderly participants have probably had previous contact with someone who was recently hospitalized. Additionally, previous contamination of the environment is also considered an important reservoir of microorganisms ${ }^{(14)}$.

Although we have found only one SCCmec type IV $p v t$, the frequency of nares colonized by MRSA $(19 \%, 4 / 21)$ were similar to those found in Mexico City, where $12.6 \%$ of $S$. aureus carriers were colonized with MRSA, both rates higher than those reported in the United States $(1.5 \%)^{(3)}$.

We compared PCR assays for the detection of the methicillin-resistance gene with classical methods in this study. The two isolates initially classified as methicillin-resistant based on disk diffusion showed discrepant results when tested with the E-test ${ }^{\circledR}$ and PCR. Investigators have reported that the conventional susceptibility testing methods, mainly the diffusion 
disk technique, are not always reliable for methicillin-resistant staphylococci detection ${ }^{(15)}$.

Molecular epidemiology studies have highlighted the global spread of different MRSA clones. HA-MRSA may have a hidden reservoir in the community just as the CA-MRSA has one in health services. This increases the need to monitor such clones $^{(14)}$. Although our isolates were not clonally typed, the presence of CA-MRSA and HA-MRSA genotypes colonizing healthy elderly participants in a multisport center emphasizes the risk of cross-transmission. The presence of different MRSA clones in this group could not be determined in our study, but warrants additional research.

In this study of healthy elderly people in Minas Gerais, Brazil, we detected the prevalence of MRSA, including CAMRSA, among $S$. aureus carriers. The importance of CAMRSA colonization as a risk factor for cross-transmission in the community must be further analyzed.

\section{ACKNOWLEDGMENTS}

The authors would like to thank Dra Kátia Regina Netto dos Santos (Institute of Microbiology Paulo de Goés, Universidade Federal do Rio de Janeiro-UFRJ) who kindly provided the control strain Clone Southwest Pacific.

\section{CONFLICT OF INTEREST}

The authors declare that there is no conflict of interest.

\section{FINANCIAL SUPPORT}

The authors would like to thank Fundação de Amparo à Pesquisa do Estado de Minas Gerais (FAPEMIG).

\section{REFERENCES}

1. Köck R, Mellmann A, Schaumburg F, Friedrich AW, Kipp F, Becker K. The Epidemiology of Methicillin-Resistant Staphylococcus aureus (MRSA) in Germany. Dtsch Arztebl Int 2011; 108:761-767.

2. David Z, Daum RS. Community-Associated Methicillin-Resistant Staphylococcus aureus: Epidemiology and Clinical Consequences of an Emerging Epidemic. Clin Microbiol Rev 2010; 23:616-687.

3. Hamdan-Partida A, Sainz-Espuñes T, Bustos-Martínez J. Isolation of community-acquired methicillin-resistant Staphylococcus aureus in healthy carriers in a Mexican community. Int J Infect Dis 2014; $18: 22-26$

4. Clinical and Laboratory Standard Institute (CLSI). Performance standards for antimicrobial susceptibility testing, Approved Standard M100-S23. CLSI; 2014. (Accessed 2014 June 20) Available at: ffile://C:/Users/User/Downloads/CLSI\%202014.pdf

5. Saïd-Salim B, Mathema B, Braughton K, Davis S, Sinsimer D, Eisner W, et al. Differential Distribution and Expression of Panton-Valentine Leucocidin among Community-Acquired Methicillin-Resistant Staphylococcus aureus Strains. J Clin Microbiol 2005; 43:3373-3379.

6. Martín-López JV, Díez-Gil O, Morales M, Batista N, Villar J, Claverie-Martín F, et al. Simultaneous PCR detection of ica cluster and methicillin and mupirocin resistance genes in catheter-isolated Staphylococcus. Int Microbiol 2004; 7:63-66.

7. Arciola CR, Baldassarri L, Montanaro L. Presence of icaA and $i c a \mathrm{D}$ genes and slime production in a collection of staphylococcal strains from catheter-associated infections. J Clin Microbiol 2001; 39:2151-2156

8. Gu J, Li H, Li M, Vuong C, Otto M, Wen Y, et al. Bacterial insertion sequence IS256 as a potential molecular marker to discriminate invasive strains from commensal strains of Staphylococcus epidermidis. J Hosp Infect 2005; 61:342-348.

9. Shopsin B, Mathema B, Alcabes P, Saïd-Salim B, Lina G, Matsuka A, et al. Prevalence of agr specificity groups among Staphylococcus aureus strains colonizing children and their guardians. J Clin Microbiol 2003; 41:456-459.

10. Cucarella C, Solano C, Valle J, Amorena B, Lasa I, Penadés JR. Bap, a Staphylococcus aureus surface protein involved in biofilm formation. J Bacteriol 2001; 183:2888-2896.

11. Tristan A, Ying L, Bes M, Etienne J, Vandenesch F, Lina G. Use of multiplex PCR to identify Staphylococcus aureus adhesins involved in human hematogenous infections. J Clin Microbiol 2003; 41:4465-4467.

12. Kondo Y, Ito T, Ma XX, Watanabe S, Kreiswirth BN, Etienne J, et al. Combination of multiplex PCRs for staphylococcal cassette chromosome mec type assignment: rapid identification system for $m e c, c c r$, and major differences in junkyard regions. Antimicrob Agents Chemother 2007; 51: 264-274.

13. Gómez P, González-Barrio D, Benito D, García JT, Viñuela J, Zarazaga M, et al. Detection of methicillin-resistant Staphylococcus aureus (MRSA) carrying the $m e c C$ gene in wild small mammals in Spain. J Antimicrob Chemother 2014; 69:2061-2064.

14. Vieira MAS. Estudo epidemiológico e molecular de portador nasal de Staphylococcus aureus e de Staphylococcus aureus meticilina resistente em Pronto Atendimento Pediátrico e em Unidades de Terapia Intensiva Neonatal de Goiânia. 2010. 96p. (Doctor's Thesis). Instituto de Patologia Tropical e Saúde Pública. Universidade Federal de Goiás; Goiânia; 2010.

15. Iraz M, Tekerekoglu MS, Otlu B, Ay S. Comparison of an automated system with four phenotypic methods for the detection of methicillin resistant Staphylococcus aureus. Afr J Microbiol Res 2012; 6:764-769. 